\title{
Nitrogen Inhibits Nodulation and Reversibly Suppresses Nitrogen Fixation in Nodules of Alnus maritima
}

\author{
M. Tiffany Laws and William R. Graves \\ Department of Horticulture, Iowa State University, Ames, IA 50011-1100
}

\begin{abstract}
AdDitional InDEX wORDS. seaside alder, actinorhizal plants, Frankia, ammonium nitrate, acetylene reduction assay
Aвstract. Symbiotic associations between Alnus maritima (Marsh.) Muhl. ex Nutt. (seaside alder) and actinomycetes in the genus Frankia Brunchorst result in root nodules in which atmospheric nitrogen $(\mathrm{N})$ is fixed. The economic and environmental benefits of $\mathrm{N}$ fixation have led to interest in inducing root nodules during production of $A$. maritima. Because woody plants produced in nurseries typically are provided $\mathbf{N}$ fertilizer, our objectives were to determine how applied $\mathbf{N}$ influences nodulation of $\boldsymbol{A}$. maritima and to characterize how short-term changes in root-zone $\mathbf{N}$ affect the function of nodules. Potted seedlings were grown in perlite that was inoculated with $30 \mathrm{~mL}$ of soil from the root zones of mature plants in their native habitat on the Delmarva Peninsula. Each pot was drenched once daily for 10 weeks with nutrient solution that contained ammonium nitrate at 10 concentrations from 0 to 8 mM. Plants that received no ammonium nitrate formed the most nodules, and nodulation decreased linearly as ammonium nitrate increased from 0.25 to 4 mM. Plants treated with ammonium nitrate at 4 or 8 mu formed nearly no nodules, while ammonium nitrate at $0.5 \mathrm{~mm}$ resulted in vigorous plants with an average nodule count of 70 . In a second experiment, a population of nodulated seaside alders was established by irrigating seedlings in inoculated perlite once daily with 0.5 -mu ammonium nitrate for 6 weeks. Plants then were provided ammonium nitrate at 0.5, 2, or 4 mm for 2 weeks. Acetylene-reduction assays showed suppressed nodule activity among plants provided 2- and 4-mu ammonium nitrate. Daily irrigation of those plants with $\mathrm{N}$-free solution subsequently led to a rapid depletion of root-zone $\mathrm{N}$ and to a concomitant resurgence of nodule activity. These results demonstrate that $\mathrm{N}$ fertilization can be managed to promote nodulation of $A$. maritima and show that decreased nodule activity caused by short-term increases in root-zone $\mathrm{N}$ is reversible.
\end{abstract}

Alnus maritima is an attractive shrub or small tree native to three small, disjunct provenances in the United States (Schrader and Graves, 2000). Like other alders, A. maritima is an actinorhizal species that forms root nodules in which Frankia fix gaseous N (Schrader and Graves, 2000; Stibolt, 1978). Unlike most woody plants that cannot benefit directly from atmospheric N, A. maritima with functional root nodules might perform well if planted in $\mathrm{N}$ poor soils. We seek to understand how the symbiosis between $A$. maritima and Frankia can be established and optimized during the culture of plants in nurseries.

Commercial production of plants with functional root nodules is important for two reasons. First, growers of nodulated A. maritima might apply less $\mathrm{N}$ fertilizer, which would reduce production costs and the potential for environmental damage caused by run-off of irrigation water. Second, the soils in which A. maritima is planted may not contain compatible Frankia; installation of nodulated plants would overcome this possible barrier to $\mathrm{N}$ fixation in the landscape. Protocols for producing nodulated A. maritima are needed. In addition, data are needed on how $\mathrm{N}$ fertilization affects the $\mathrm{N}$ fixation of nodulated plants, and comparisons of the growth of plants reliant on fixed $\mathrm{N}$ and those supplied $\mathrm{N}$ fertilizer would help producers assess the practicality of reducing $\mathrm{N}$ fertilization.

Formation of functional nodules on actinorhizal plants requires the presence of compatible Frankia in edaphic environments conducive to bacterial infection, nodule development, and the activity of nitrogenase. Although numerous physical and chemical factors may govern the nodulation of A. maritima and the function of its

Received for publication 8 Nov. 2004. Accepted for publication 29 Jan. 2005. Journal paper of the Iowa Agriculture and Home Economics Experiment Station, Ames, IA, Project No. 3603, and supported by the Hatch Act and State of Iowa funds. nodules, $\mathrm{N}$ content of the root zone might be the most important during production of plants in nurseries. Researchers working with other alders have demonstrated that high $\mathrm{N}$ concentrations restrict nodule formation and activity (Berry and Torrey, 1985; Gentili and Huss-Danell, 2003; Ingestad, 1980; Kohls and Baker, 1989). Huss-Danell et al. (1982) showed that 20-mm ammonium chloride damages the vesicles of Frankia and reduces nitrogenase activity in nodules of Alnus incana (L.) Moench, an effect that was reversed after ammonium chloride applications were reduced. Burgess and Peterson (1987) suggested using low-N fertilizers to permit nodule formation and $\mathrm{N}$ fixation of Alnus japonica (Thunb.) Steud. However, no such data have been generated for A. maritima.

Our first objective was to define how various concentrations of ammonium nitrate affect the nodulation of A. maritima and the subsequent fixation of $\mathrm{N}$. Our second objective was to determine how short-term increases and decreases in applied root-zone $\mathrm{N}$ influence $\mathrm{N}$ fixation using a population of plants with copious, active nodules. Ammonium nitrate was the $\mathrm{N}$ source used to meet both objectives because it often is used commercially. Also, unlike other common $\mathrm{N}$ sources, varying the rate at which ammonium nitrate is applied does not directly alter the concentrations of other ions. The results of these experiments enhance our understanding of symbioses of actinorhizal plants and will be useful to growers who want to ensure that their A. maritima possess numerous root nodules in which $\mathrm{N}$ is fixed at high rates.

\section{Materials and Methods}

N EFFECTS ON ESTABLISHMENT OF SYMBIOSES. Cold-stratified seeds $(\mathrm{n}=675)$ of A. maritima ssp. maritima indigenous to $\approx 38^{\circ} 36^{\prime} \mathrm{N}$ lat., $75^{\circ} 30^{\prime} \mathrm{W}$ long. on the Delmarva Peninsula were germinated in clay pots (top diameter $=7 \mathrm{~cm}$, height $=9.5 \mathrm{~cm}$ ) 
filled with coarse perlite and a 3-cm-deep layer of fine-grade vermiculite directly around the seeds. The pots were kept moist with nitrate-free tap water in a greenhouse in which the air temperature was 18 to $30^{\circ} \mathrm{C}$ and natural irradiance was supplemented by use of incandescent lamps that provided $<100 \mu \mathrm{mol} \cdot \mathrm{m}^{-2} \cdot \mathrm{s}^{-1}$ photosynthetically active radiation $(P A R)$ and $16-\mathrm{h}$ photoperiods. Seedlings were fertilized twice daily with $18-\mathrm{mm} \mathrm{N}$ from a blend (1:3, by weight) of water-soluble Peters Excel All-Purpose and Peters Excel Cal-Mag (17N-2.2P-13.3K) (Scotts Sierra Horticultural Products, Marysville, Ohio). Research with other alders and our informal observations of A. maritima indicated $18-\mathrm{mm}$ $\mathrm{N}$ would prevent root nodulation.

Eighty one-month-old seedlings of uniform size were transplanted from the clay pots to individual plastic pots (top diameter $=12.5 \mathrm{~cm}$, height $=11.5 \mathrm{~cm}$ ). The medium was coarse perlite to which $30 \mathrm{~mL}$ of soil was added per pot as inoculum to provide compatible Frankia. The soil was from the root zones of naturally occurring, mature A. maritima on the Delmarva Peninsula and was placed in the upper $2 \mathrm{~cm}$ of perlite. Treatments began on 10 Apr. 2003 when the seedlings had two fully expanded true leaves. Each seedling was regarded as an experimental unit, and a randomized complete-block design was used. Eight seedlings were assigned randomly to each of 10 treatments to provide plants with various amounts of N. A quarter-strength, N-free Hoagland solution (Hoagland and Arnon, 1950), modified to provide half of the prescribed $\mathrm{Fe}$, was supplemented with ammonium nitrate at $0,0.25,0.5,0.75,1.0,1.25,1.5,2.0,4.0$, or $8.0 \mathrm{~mm}$. The $\mathrm{pH}$ of all 10 solutions was 5.5. Each plant was irrigated to container capacity with $300 \mathrm{~mL}$ of its prescribed solution on the day of transplanting and inoculation (day 0) and irrigated once daily thereafter with treatment solution. Air temperature in the greenhouse ranged from 23 to $30^{\circ} \mathrm{C}$, and midday $P A R$ was as high as $550 \mu \mathrm{mol} \cdot \mathrm{m}^{-2} \cdot \mathrm{s}^{-1}$.

After 10 weeks, $\mathrm{N}$ fixation of eight randomly selected plants from three ammonium nitrate treatments was estimated using an acetylene reduction assay (Hardy et al., 1968; Huss-Danell, 1978). Each root system was placed in a 1-L mason jar, and airtight seals were created around the stems protruding through the openings in the lids. We removed $100 \mathrm{~mL}$ of the atmosphere from each jar and replaced it with $100 \mathrm{~mL}$ of ultra-high-purity acetylene. Linearity of ethylene production for over $30 \mathrm{~min}$ and undetectable endogenous ethylene from roots after $30 \mathrm{~min}$ without acetylene were confirmed in preliminary work. Therefore, a 1$\mathrm{mL}$ sample was removed with a gas-tight syringe after $30 \mathrm{~min}$, reduced to $0.1 \mathrm{~mL}$, and brought back to $1 \mathrm{~mL}$ with air. A Varian 3600 Star CX gas chromatograph (Varian, Palo Alto, Calif.) was used to analyze the sample for ethylene. Reduction of acetylene to ethylene by nitrogenase indirectly represents $\mathrm{N}$-fixation activity. The assays were performed in the greenhouse during the middle of the photoperiod. Immediately afterwards, the total number of nodules per plant and the leaf surface area (LI-3100 area meter; LI-COR, Lincoln, Nebr.) of all plants were determined. We expressed nodule counts on a per-plant basis because there was no treatment effect on root dry weight. Plant height was measured, and nodules, stems, leaves, and roots were weighed separately after they were dried at $67^{\circ} \mathrm{C}$ for $7 \mathrm{~d}$. Total $\mathrm{N}$ content of dried leaves from plants treated with ammonium nitrate at $0,0.5,1,2$, and $8 \mathrm{~mm}$ was determined. The dependent variables were regressed over the $\mathrm{N}$ concentrations applied in irrigation solutions.

ROOT-ZONE N EFFECTS ON NODULE FUNCTION. This experiment was conducted in a greenhouse in which the air temperature ranged from 24 to $32{ }^{\circ} \mathrm{C}$ and $P A R$ was as high as $590 \mu \mathrm{mol} \cdot \mathrm{m}^{-2} \cdot \mathrm{s}^{-1}$. Indi- vidually potted seedlings were experimental units in a completely randomized design. Phase one of this experiment began with establishing a population of seedlings by using the methods described for the first experiment. Sixty seedlings were transplanted when they were 6 weeks old by using the same materials as in the first experiment. Beginning on 3 July 2003, the 60 pots were irrigated once daily for 7 weeks with a base solution supplemented with $0.5-\mathrm{mm}$ ammonium nitrate, one of the solutions used in the first experiment. This $\mathrm{N}$ concentration was selected because it led to vigorous plants with many root nodules during the first experiment. At the conclusion of phase one, we had 60 robust plants that we presumed had numerous root nodules.

Phase two began by randomly assigning 20 of the plants to each of three treatments, which were application of ammonium nitrate at $0.5,2$, and $4 \mathrm{~mm}$ once daily. Four plants from each of the three treatments were chosen randomly and harvested after 2 weeks. Acetylene-reduction assays, nodule counts, and plant size were determined as in the first experiment. The 48 remaining plants, 16 in each of the phase-two treatments, entered phase three that day and were irrigated thereafter once daily with the base nutrient solution with no ammonium nitrate. Four plants from each phase-two treatment were harvested after 1, 2, 4, or 8 weeks. Acetylene-reduction assays, nodule counts, and plant size were determined at each harvest. Perlite from pots of all plants harvested after 1 and 2 weeks of phase three was analyzed for total $\mathrm{N}$ content. The dry, ground sample was burned in a combustion tube at $950{ }^{\circ} \mathrm{C}$, and exhaust gases were collected. Gaseous $\mathrm{N}$ was measured by thermal conductivity with a Leco CHN 2000 (Leco Corp., St. Joseph, Mich.).

DATA ANALYSIS. Data from both experiments were analyzed by using SAS (version 8E; SAS Inst., Cary, N.C.), and analysis of variance was performed by using the general linear model for least square means. Values of $P>0.05$ led to the rejection of hypotheses. For experiment two, effects of ammonium nitrate, time, and their interaction were partitioned. Version 8.0 of SigmaPlot (SPSS, Chicago) was used to perform linear regression analyses over time and concentrations of ammonium nitrate.

\section{Results}

NefFeCtS ON ESTABLISHMENT OF SYMBIOSES. Mean nodule count for plants that received no ammonium nitrate exceeded 100 and was $\approx 30$ more than the mean nodule count for plants provided ammonium nitrate at $0.25 \mathrm{~mm}$ (Fig. 1). Nodule count decreased linearly as applied ammonium nitrate increased from 0.25 to $4 \mathrm{~mm}$ (Fig. 1). The 4-mm treatment led to a mean nodule count of 0.3 per plant, whereas 8-mм ammonium nitrate prevented nodulation (Fig. 1). Acetylene reduction to ethylene was minimal among the nodule-free root systems in the 8-mm treatment, whereas root systems provided no ammonium nitrate yielded the greatest ethylene production at nearly $0.71 \mu \mathrm{mol} \cdot \mathrm{h}^{-1}$ per plant during the 30-min assays (Fig. 1). Regressing acetylene reduction per root system across the three ammonium nitrate treatments for which assays were run resulted in a linear relationship: ethylene $=1.1$ -0.34 (ammonium nitrate); $r^{2}=0.78$. Treatment effects on mean dry weight of nodules per plant were consistent with nodule counts, and dividing nodule masses by nodule counts revealed that the mean dry mass of an individual nodule, $0.77 \mathrm{mg}$, was similar among treatments. Mean plant height decreased linearly, and mean total $\mathrm{N}$ content of leaves increased linearly, as applied ammonium nitrate increased (Fig. 2). Stems of plants that received no ammonium nitrate appeared less stout and erect than stems of 
$\mathrm{C}_{2} \mathrm{H}_{2}$ reduction $\left(\mu \mathrm{mol} \cdot \mathrm{h}^{-1}\right.$ per plant $\left.\mathrm{C}_{2} \mathrm{H}_{4}\right)$



Fig. 1. Nodule count of greenhouse-grown, potted seedlings of Alnus maritima ssp. maritima irrigated once daily with nutrient solutions that contained $\mathrm{N}$ as ammonium nitrate at $0,0.25,0.5,0.75,1.0,1.25,1.5,2.0,4.0$, or $8.0 \mathrm{~mm}$ for 10 weeks. Each symbol represents a mean of eight single-plant replicates. Plants were inoculated with soil that contained Frankia compatible with Alnus maritima. A linear regression function is shown to describe the relationship between ammonium nitrate at 0.25 to $4 \mathrm{~mm}$ and mean nodule count. Mean ( $\mathrm{n}=$ 8 ) nodule activity per root system in three treatments is expressed as acetylene reduced to ethylene, with standard-error values shown in parentheses. At the top of the figure, arrows show that nodule-activity data are provided for plants treated with ammonium nitrate at 0,1 , and $8 \mathrm{~mm}$.

plants in other treatments. Ammonium nitrate did not influence root $(P>0.167)$, stem $(P>0.917)$, or leaf $(P>0.703)$ dry mass, nor was leaf surface area affected $(P>0.085)$.

RoOT-ZONE N EFFECTS ON NODULE FUNCTION. Nodulation of all harvested plants at the end of phase two was profuse but not quantified, and mean acetylene reduction to ethylene per root system ranged from $\approx 0.6$ to $2.4 \mu \mathrm{mol} \cdot \mathrm{h}^{-1}$ per plant among plants in the three ammonium nitrate treatments (Fig. 3). No differences based on the concentration of ammonium nitrate applied during phase two existed after $1,2,4$, or 8 weeks of phase three, and therefore, data from all phase-two treatments were combined for analysis of time effects during phase three. Mean acetylene reduction to ethylene per root system during the 30-min assays increased linearly from about 1 to $2.2 \mu \mathrm{mol} \cdot \mathrm{h}^{-1}$ per plant over the 8 weeks of phase three (Fig. 3). Analyses of perlite during phase three confirmed that $\mathrm{N}$ was leached rapidly from the root zones. No differences associated with phase-two treatments existed in the $\mathrm{N}$ content of the perlite when our first data were collected after 1 week of phase three.

\section{Discussion}

Our results illustrate the dynamic relationship between rootzone $\mathrm{N}$ content and the formation and function of $\mathrm{N}$-fixing symbioses on roots of $A$. maritima. Nodule count and $\mathrm{N}$-fixing activity per root system decrease as the concentration of applied $\mathrm{N}$ increases, and nodulation is nearly or completely prevented when ammonium nitrate is applied at concentrations $\geq 4 \mathrm{~mm}$ (Fig. 1). Activity of nodules that form in low-N root zones is sensitive to changes in N. Decreases in activity caused by short-term increases in $\mathrm{N}$ are reversed rapidly as root-zone $\mathrm{N}$ declines (Fig.



Ammonium nitrate $(\mathrm{mM})$

Fig. 2. Plant height and leaf N concentration of greenhouse-grown, potted seedlings of Alnus maritima ssp. maritima irrigated once daily with nutrient solutions that contained $\mathrm{N}$ as ammonium nitrate at $0,0.25,0.5,0.75,1.0,1.25,1.5,2.0,4.0$, or $8.0 \mathrm{~mm}$ for 10 weeks. Each symbol representing height is a mean of eight single-plant replicates. Each symbol representing leaf $\mathrm{N}$ content is a mean of three single-plant replicates.



Fig. 3. Nodule activity, as indicated by the reduction of acetylene to ethylene, of greenhouse-grown, potted seedlings of Alnus maritima ssp. maritima at the end of phase two (week 0 of phase three) and after 1, 2, 4, or 8 weeks of phase three. Each symbol at week 0 represents a mean of four single-plant replicates, and the ammonium nitrate treatments applied during phase two are indicated in parentheses. Data for the four replicates from each phase-two treatment were combined because no treatment difference existed during phase three. Each of the symbols from weeks 1 through 8 represents a mean of 12 single-plant replicates irrigated once daily with an $\mathrm{N}$-free solution during the 8 weeks of phase three.

$3)$. Producers of $A$. maritima can use these data to manage $\mathrm{N}$ applications to ensure nodulation, $\mathrm{N}$ fixation, and minimal waste of $\mathrm{N}$ fertilizers. Our results also show that growers and landscape managers may reverse the deleterious effects on $\mathrm{N}$ fixation of inadvertent increases in root-zone $\mathrm{N}$ by leaching $\mathrm{N}$ from the adjacent substrate.

The $\mathrm{N}$-induced reduction in nodule formation and activity we observed is consistent with previous research on other species of alder. Kohls and Baker (1989) found that nodulation of Alnus glutinosa (L.) Gaertn. is negatively correlated with root-zone N 
concentration and is completely inhibited when $\mathrm{N}$ exceeds $2 \mathrm{~mm}$, possibly because of damage to the vesicles of Frankia (Huss-Danell et al., 1982). Although the response of A. maritima was similar, regression analysis did not predict that 2- to 4-mM ammonium nitrate completely inhibits nodule formation (Fig. 1). This suggests that nodulation of $A$. maritima may be less sensitive to $\mathrm{N}$ than is nodulation of A. glutinosa, but direct comparisons of the two species are needed. Our results are attributable directly to $\mathrm{N}$ because other nutrient elements were not varied and the $\mathrm{pH}$ of all solutions was 5.5. In addition, a preliminary study we conducted showed that daily irrigation to container capacity prevented changes $>1 \mathrm{pH}$ unit between irrigations. It was important for us to maintain uniform $\mathrm{pH}$ among treatments because numerous researchers, beginning with Quispel (1958), have characterized $\mathrm{pH}$ effects on nodulation. Berry and Torrey (1985) considered pH 5.5 optimal for nodulation and reported that $\mathrm{pH}<4.5$ inhibits the formation of nodules on roots of A. glutinosa, Alnus incana ssp. rugosa (L.) Furlow, and Alnus rubra Bong.

Most of the many nodules observed after phase two of our second experiment likely formed as plants received 0.5-mm ammonium nitrate during the first phase, thereby substantiating the effect of 0.5-mM ammonium nitrate documented during the first experiment. In addition, data collected at the end of phase two of the second experiment provide evidence that the activity of nodules formed under low-N conditions is suppressed rapidly upon exposure to increased N. Phase three was designed to test whether this suppression was reversible, and treatment differences no longer existed after daily application of $\mathrm{N}$-free solution for 1 week (Fig. 3). Analysis of the perlite confirmed a rapid leaching of $\mathrm{N}$ concomitant with increased nodule activity. Huss-Danell et al. (1982) similarly documented recovery of nodule activity among plants of $A$. incana after a short-term exposure to $20-\mathrm{mm}$ ammonium chloride. Considered collectively, the three phases of the second experiment illustrate the dynamic influence of $\mathrm{N}$ during establishment and function of $\mathrm{N}$-fixing symbioses on roots of A. maritima. Producers of this species, and managers of $A$. maritima installed in the landscape, should recognize that low $\mathrm{N}$ promotes nodulation and that increases in $\mathrm{N}$ due to fertilization or other causes will reduce nodule function until $\mathrm{N}$ concentrations in the root zone are reduced.

We have reached several important conclusions regarding how $\mathrm{N}$ affects symbioses between A. maritima and Frankia, but several issues remain unresolved. Whether ammonium and nitrate influence the symbioses to the same extent and via similar mechanisms is unclear. How long nodulated plants can be exposed to $\mathrm{N}$ concentrations that inhibit $\mathrm{N}$ fixation without causing irreversible damage to the symbioses is another relevant issue. Whether it is necessary to inoculate A. maritima with Frankia, and if so, whether it is critical to provide bacteria from the soils where the species is native are unknown. We occasionally find nodules on uninoculated plants cultured in medium without soil, but data are needed on the ubiquity and functional variability of Frankia compatible with $A$. maritima. The conclusions we have drawn regarding $\mathrm{N}$ effects can serve as a basis for developing new hypotheses regarding these unresolved issues. Moreover, our findings demonstrate that the dry mass and leaf surface area of A. maritima produced with little or no applied $\mathrm{N}$ can be similar to those traits of $A$. maritima provided luxurious concentrations of ammonium nitrate if compatible Frankia are present in root zones. Although application of no $\mathrm{N}$ evoked the most nodules (Fig. 1), we observed that shoot systems of plants in that treatment were shaped irregularly and had leaves that were not as intensely green as the foliage of plants in the other treatments. Therefore, we recommend use of ammonium nitrate at 0.5 to 2 mu to enhance leaf $\mathrm{N}$ content and reduce height (Fig. 2) of plants with a large number of active root nodules (Fig. 1).

\section{Literature Cited}

Berry, A.M. and J.G. Torrey. 1985. Seed germination, seedling inoculation and establishment of Alnus spp. in containers in greenhouse trials. Plant Soil 87:161-173.

Burgess, D. and R.L. Peterson. 1987. Effect of nutrient conditions on root nodule development in Alnus japonica. Can. J. Bot. 65:1658-1670.

Gentili, F. and K. Huss-Danell. 2003. Local and systemic effects of phosphorus and nitrogen on nodulation and nodule function in Alnus incana. J. Expt. Bot. 54:2757-2767.

Hardy, R.W.F., R.D. Holsten, E.K. Jackson, and R.C. Burns. 1968. The acetylene-ethylene assay for $\mathrm{N}_{2}$ fixation: Laboratory and field evaluation. Plant Physiol. 43:1185-1207.

Hoagland, D.R. and D.I.Arnon. 1950. The water culture method for growing plants without soil. Calif. (Berkeley) Agr. Expt. Sta. Circ. 347.

Huss-Danell, K. 1978. Nitrogenase activity measurements in intact plants of Alnus incana. Physiol. Plant. 43:372-376.

Huss-Danell, K., A. Sellstedt, A. Flower-Ellis, and M. Sjöström. 1982. Ammonium effects on function and structure of nitrogen-fixing root nodules of Alnus incana (L.) Moench. Planta 156:332-340.

Ingestad, T. 1980. Growth, nutrition, and nitrogen fixation in grey alder at varied rate of nitrogen addition. Physiol. Plant. 50:353-364.

Kohls, S.J. and D.D. Baker. 1989. Effects of substrate nitrate concentration on symbiotic nodule formation in actinorhizal plants. Plant Soil 118:171-179.

Quispel, A. 1958. Symbiotic nitrogen fixation in nonleguminous plants. IV. The influence of some environmental conditions on different phases of the nodulation process in Alnus glutinosa. Acta Bot. Neerland. 7:191-204.

Schrader, J.A. and W.R. Graves. 2000. Alnus maritima: A rare woody species from the New World. New Plantsman 7:74-82.

Stibolt, V.M. 1978. The ecology and systematics of Alnus maritima Muhl. ex Nutt. (Betulaceae). MS Thesis, Dept. of Botany, Univ. of Maryland, College Park. 